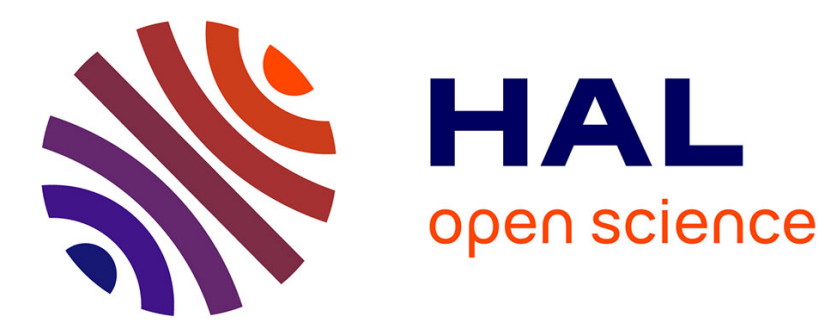

\title{
Experimental study of airflow and heat transfer above a hot liquid surface simulating a cup of drink
}

\author{
Onrawee Laguerre, V. Osswald, Hong-Minh Hoang, Isabelle I. Souchon, \\ Ioan-Cristian Trelea, Christoph Hartmann, Denis Flick
}

\section{- To cite this version: \\ Onrawee Laguerre, V. Osswald, Hong-Minh Hoang, Isabelle I. Souchon, Ioan-Cristian Trelea, et al.. Experimental study of airflow and heat transfer above a hot liquid surface simulating a cup of drink. Journal of Food Engineering, 2017, 197, pp.24-33. 10.1016/j.jfoodeng.2016.10.014 . hal-01555733}

\section{HAL Id: hal-01555733 \\ https://hal.science/hal-01555733}

Submitted on 4 Jul 2017

HAL is a multi-disciplinary open access archive for the deposit and dissemination of scientific research documents, whether they are published or not. The documents may come from teaching and research institutions in France or abroad, or from public or private research centers.
L'archive ouverte pluridisciplinaire HAL, est destinée au dépôt et à la diffusion de documents scientifiques de niveau recherche, publiés ou non, émanant des établissements d'enseignement et de recherche français ou étrangers, des laboratoires publics ou privés. 


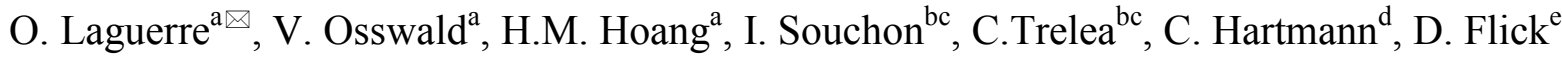

4
${ }^{\text {a }}$ Irstea, UR GPAN, 1 rue Pierre-Gilles de Gennes, 92761 Antony, France

${ }^{\mathrm{b}}$ INRA, UMR782 GMPA, 78850 Thiverval Grignon, France

${ }^{\mathrm{c}}$ AgroParisTech, UMR782 GMPA, 78850 Thiverval Grignon, France

${ }^{\mathrm{d}}$ Nestlé Research Center, CH-1000 Lausannen, Swittzerland

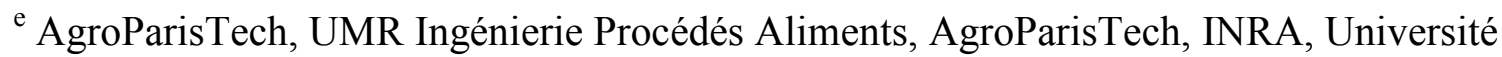
Paris Saclay, F-91300 Massy, France

\section{Abstract}

This work was carried out to study the airflow and heat transfer above a cup of hot drink. The experiment was undertaken in a device in which the air temperature and velocity were controlled representing a room condition. The influence of heat exchange by convection and evaporation between the hot drink (at different temperatures) and air on the velocity and temperature fields above the cup is presented. An experimental methodology was developed to evaluate the heat transfer coefficient between the air and hot drink with and without evaporation.

The airflow visualisation by PIV (Particle Imagery Velocimetry) above the cup shows that the flow is complex with unsteady plumes detachment and vortex formation. The combined convection and evaporation lead to upward airflow with temperature fluctuations which become significant for drink temperature above $55^{\circ} \mathrm{C}$. This can be explained by the non-

\footnotetext{
${ }^{\square}$ Corresponding author: Tel: 33140966121 Fax: 33140966075 E-mail: onrawee.laguerre@irstea.fr
} 
23 linearity between saturated pressure of water and its temperature. This work could highlight

24 how volatile aromas are released from hot drink.

25

26 Keywords: convection, evaporation, airflow, hot drink, air

\section{Nomenclature}

\begin{tabular}{|c|c|c|}
\hline A & surface area & $\mathrm{m}^{2}$ \\
\hline $\mathrm{D}$ & cylinder diameter & $\mathrm{m}$ \\
\hline $\mathrm{L}$ & characteristic length & $\mathrm{m}$ \\
\hline$f$ & frequency of vortex shedding & $\mathrm{Hz}$ \\
\hline g & gravitational acceleration & $\mathrm{m} \cdot \mathrm{s}^{-2}$ \\
\hline $\mathrm{h}$ & convective heat transfer coefficient & $\mathrm{W} \cdot \mathrm{m}^{-2} \cdot \mathrm{K}^{-1}$ \\
\hline M & molecular weight & $\mathrm{kg} / \mathrm{mol}$ \\
\hline Q & heat exchange & $\mathrm{W}$ \\
\hline $\mathrm{t}$ & time & $\mathrm{s}$ \\
\hline $\mathrm{T}$ & temperature & ${ }^{\circ} \mathrm{C}$ \\
\hline $\mathrm{V}$ & velocity & $\mathrm{m} \cdot \mathrm{s}^{-1}$ \\
\hline
\end{tabular}

\section{Greek symbols}

$\beta \quad$ thermal expansion coefficient $\quad \mathrm{K}^{-1}$

$\rho \quad$ density of the fluid $\quad \mathrm{kg} \cdot \mathrm{m}^{-3}$ 

$v \quad$ kinematic viscosity
$\mathrm{m}^{2} \cdot \mathrm{s}^{-1}$
thermal diffusivity
$\mathrm{m}^{2} \cdot \mathrm{s}^{-1}$

$\alpha$

\section{Dimensionless Number}

\begin{tabular}{|c|c|}
\hline $\begin{array}{l}\text { Reynolds number } \\
\operatorname{Re}_{\mathrm{L}}=\frac{\mathrm{v}_{\infty} \mathrm{L}}{\mathrm{v}}\end{array}$ & $\begin{array}{l}\text { Characterization of flow regimes for forced convection: laminar or } \\
\text { turbulent flow }\end{array}$ \\
\hline $\begin{array}{l}\text { Grashof number } \\
\mathrm{Gr}_{\mathrm{L}}=\frac{\mathrm{g} \beta\left(\mathrm{T}_{\mathrm{w}}-\mathrm{T}_{\infty}\right) \mathrm{L}^{3}}{v^{2}}\end{array}$ & Ratio of buoyancy to viscous force acting on a fluid \\
\hline $\begin{array}{l}\text { Prandt number } \\
\operatorname{Pr}=\frac{v}{\alpha}=0.71 \text { for air }\end{array}$ & Ratio of momentum diffusivity to thermal diffusivity \\
\hline $\begin{array}{l}\text { Rayleigh number } \\
\operatorname{Ra}_{\mathrm{L}}=\mathrm{Gr}_{\mathrm{L}} \cdot \operatorname{Pr}_{\mathrm{L}}\end{array}$ & $\begin{array}{l}\text { Characterization of flow regime for natural convection: laminar or } \\
\text { turbulent flow }\end{array}$ \\
\hline $\begin{array}{l}\text { Nusselt number } \\
\mathrm{Nu}_{\mathrm{L}}=\frac{h \cdot \mathrm{L}}{\lambda_{\text {air }}}\end{array}$ & Ratio of convective to conductive heat transfer \\
\hline $\begin{array}{l}\text { Richardson number } \\
\operatorname{Ri}_{\mathrm{L}}=\frac{\mathrm{Gr}_{\mathrm{L}}}{\operatorname{Re}_{\mathrm{L}}^{2}}\end{array}$ & $\begin{array}{l}\text { Characterization of the importance of natural convection relative to } \\
\text { forced convection }\end{array}$ \\
\hline
\end{tabular}


Strouhal number

$\mathrm{St}=\frac{\mathrm{fD}}{\mathrm{V}}$

Dimensionless frequency of oscillating flow

\section{Introduction}

Odour during food consumption largely influences perception of foods and is thus determinant in consumer preference. Food aroma compounds are released to ambient air and are responsible for the ambient smell of the room where the food is consumed. The ambient smell greatly influences food intake and food choice (Stroebele and De Castro, 2004). To be able to better understand the impact of smell ambient due to food on consumer behaviour, it is first necessary to identify key room factors impacting aroma release to ambient air. Aroma release phenomena involve multi-factorial and complex processes. In the case of a cup of hot drink, it consists in aroma diffusion to liquid surface, aroma transportation to the surrounding air due to diffusion, convection and compounds/water mixture evaporation through a boundary layer (located above liquid surface). Then, aroma compounds follow airflow in the room and arrive to the consumer nose. This study focuses only on the airflow, heat and vapour transfer just above the cup. The understanding of these mechanisms is a first step useful for understanding and controlling the aroma perception by consumer.

\subsection{Studies on aroma compounds in foods}

Aroma, which is one of the key components of food flavour, depends on the type and concentration of volatile compounds present in the air above the food and in the oral cavity

51 during eating, and how they interact with appropriate sensory receptors in nose when they are 52 carried by the breath of the individual (Overbosch et al., 1991; Taylor and Linforth, 1996). 
Many studies highlighted the influence of physicochemical properties of aroma compounds (volatility, hydrophobicity), the released amounts and kinetics, for model food (Landy et al., 1998; Marin et al., 1999, Carey et al., 2002; Philippe et al., 2003; Rabe et al., 2004; Meynier et al., 2005; Giroux et al., 2007) and real food (Doulia et al., 2000; Doyen et al., 2001; Roberts et al., 2003; Relkin et al., 2004, Deleris et al., 2009). In the case of real food, products are generally complex. Thus, global characterization and determination of apparent properties are often the most convenient ways to represent transport properties and explain release profiles. For solid foods, aroma release is often limited by the diffusion inside the food. For liquid foods, especially drinks of low viscosity, release is also controlled by the transport phenomena from the liquid/air interface to surrounding air (Marin et al, 1999).

\subsection{Airflow and heat transfer between object and air}

The exchange between the hot drink and the ambient air can be due to natural or forced convection. To understand the airflow, heat and water transfer between a cup of hot drink and air, the simplest way is to consider the similar phenomena occurring above a heated horizontal flat plate. Another way is to consider the cup as a cylindrical obstacle of airflow. A literature review of air flows over a flat plate and around a cylinder is, thus, presented below.

Over an isothermal flat plate, a laminar flow is first observed, then after a certain flow length (called critical length) the flow becomes unstable and turbulent. This instability occurs usually when $\operatorname{Re} \approx 3 \cdot 10^{5}$ (DeWitt, 1990).

Different flow patterns occur around a cylinder in function of air velocity. For $\operatorname{Re}<<1$, the flow smoothly divides and reunites around the cylinder. For $\mathrm{Re} \approx 10$, the flow separates in the downstream and the wake is formed by two symmetric eddies. The eddies remain steady and symmetrical but grow in size up to a Reynolds number of about 90 . At $\operatorname{Re} \geq 90$, the 
Natural convection, here $\mathrm{L}$ is the surface area divided by the perimeter:

$$
\begin{array}{lll}
\overline{\mathrm{Nu}}_{\mathrm{L}}=0.54 \mathrm{Ra}_{\mathrm{L}}^{1 / 4} & 10^{4} \leq \mathrm{Ra}_{\mathrm{L}} \leq 10^{7} & \text { Laminar flow } \\
\overline{\mathrm{Nu}}_{\mathrm{L}}=0.15 \mathrm{Ra}_{\mathrm{L}}^{1 / 3} & 10^{7} \leq \mathrm{Ra}_{\mathrm{L}} \leq 10^{11} & \text { Turbulent flow }
\end{array}
$$




$$
\begin{array}{lll}
\overline{\mathrm{Nu}}_{\mathrm{L}}=0.664 \operatorname{Re}_{\mathrm{L}}^{1 / 2} \operatorname{Pr}^{1 / 3} & \operatorname{Re}_{\mathrm{L}} \leq 2500 & \text { Laminar flow } \\
\overline{\mathrm{Nu}}_{\mathrm{L}}=0.037 \operatorname{Re}_{\mathrm{L}}^{0.8} \operatorname{Pr}^{1 / 3} & \operatorname{Re}_{\mathrm{L}}>2500 & \text { Turbulent flow }
\end{array}
$$

97 The Richardson number $\left(\mathrm{Ri}=\mathrm{Gr} / \mathrm{Re}^{2}\right)$ indicates the importance of natural convection relative to the forced convection. Typically, the natural convection is considered when $\mathrm{Ri}>10$ (negligible forced convection), mixed convection when $0.1<\mathrm{Ri}<10$ and forced convection is considered when $\mathrm{Ri}<0.1$ (negligible natural convection) (Incropera and Dewitt, 1966).

101 Most of the studies found in the literature about fluid flow and heat transfer around complex 102 obstacles are applied to building air conditioning, heat exchangers and electronic equipment cooling. In these applications, various obstacles are employed to alter the flow pattern and which leads to locally increase or decrease heat exchange. The experimental studies are rare in comparison with the numerical ones because of the metrology difficulties and cost. Several authors reported that the fluid flow over blocks is complicated unsteady motion and the

107 average flow often looks very different from the instantaneous flow (Rahman et al, 2008; 2009; Chyu and Natarajan, 1996). Although the geometry has a symmetry plane, the instantaneous velocity field is not symmetric while the time average flow must be symmetric.

Looking only the time-averaged flow may give an erroneous impression.

111 Wietrzak and Poulikakos (1990), Yong and Vafai (1998), Alamyane and Mohamad (2010),

112 Moussaoui et al (2010) numerically studied the forced convection of a heated obstacle 113 mounted on a channel wall. The characterisation of flow field surrounding the obstacle and 114 the local Nusselt number $(\mathrm{Nu})$ distribution were presented. It was shown that the obstacle 115 height/width ratio, the thermal conductivity of solid and fluid ratio, the flow rate (Re number) 116 and the heating method can produce significant effects on the flow characteristic and heat 117 transfer coefficient. Increase in the obstacle height strengthened fluid recirculation before, 118 after and upon the top surface of obstacle, thus increasing the Nusselt number. The changes in 
119 obstacle size or shape can lead to Nusselt number increases as high as $40 \%$ (Jubran et al, 120 1996) and mass transfer enhancements up to two times (Sparrow et al. 1982, 1984). Heat 121 transfer and airflow by mixed convection around a hollow cylinder placed in a ventilated cavity was studied by Mamun et al (2010). A wide range of pertinent parameters such as Rayleigh number (0-105), Richardson number (0.0-5.0), dimensionless cylinder diameter

$124(0.2-0.5)$ and the solid-fluid thermal conductivity ratio (0.2-10.0) are considered for Reynolds number $=100$. It is observed that the cylinder diameter has significant effect on both the flow and thermal fields but the solid-fluid thermal conductivity ratio has significant effect only on the thermal field. As our best knowledge, few studies were carried out in the case of partially hollow cylinder which corresponds to a cup partially filled with drink.

129 Our literature study has shown a lack of knowledge on the mechanism of the combined

130 airflow, heat and water transfer around an obstacle applied to the case of a cup of hot drink.

131 To complete this knowledge, this study was carried out. The objectives of this work were,

132 firstly, to develop a methodology of measurement of air velocity field above a cup filled with 133 hot water by PIV (Particle Imagery Velocimetry) and to study the influence of water 134 temperature on air velocity field above the cup. Secondly, to measure the heat transfer 135 coefficient between the water in the cup and the surrounding air. This coefficient determines 136 the water temperature decreasing rate. It is to be reminded that two heat transfer modes take 137 place between the water in the cup and the air: convection and evaporation. The natural 138 convection is related to the temperature difference between water and air, forced convection 139 has also to be considered if the ambient air circulates due to room ventilation. The final 140 practical objective of this work is to optimize the serving manner and the cup design in such a 141 way that the consumer perceives as much as possible the aroma of hot drink. 


\subsection{Experimental device}

145 To represent room condition, the experiment was carried out in a device specifically 146 developed for this study, in which the ambient temperature and velocity were controlled

147 (Figure 1). This device is composed of 2 parts. In the part 1, a honeycomb was used over a 148 cross section in order to avoid developing flow effects. In the part 2, the work zone was 149 equipped with two glass walls (front and top). Two fans located at the vertical right hand side 150 wall allow low air velocities in the work zone by air extraction. The work zone is equipped 151 with an anemometer (air velocity sensor), thermocouple (temperature sensor) and hygrometer 152 (air humidity sensor).

\subsection{Air velocity field measured by PIV (Particle Image Velocimetry)}

155 Oil smoke was use as tracer for the air velocity measurement by PIV. The diameter of smoke

156 particles $(\sim 1 \mu \mathrm{m}$, manufacturer data) is very small so that they follow the airflow.

157 Figure 2 shows the 2-Dimensional PIV system (LaVision Company). It is composed of CCD 158 camera (12 bits double matrices of $1376 \times 1024$ pixels) allowing the acquisition of 2 images 159 successively within a short time interval. The sequence of images taken by the camera is 160 synchronised with the 2 laser impulsions (4 couples of images per second). An instantaneous 161 air velocity field is obtained by inter-correlation of 2 successive images of smoke particles 162 presented in a strongly enlightened plan. In our case, a good velocity estimation could be 163 obtained with $6.5 \mathrm{~ms}$ between 2 laser pulses for the image dimension (width $\mathrm{x}$ height) of 7.2 $164 \mathrm{~cm} \times 8.7 \mathrm{~cm}$. Vector calculation was undertaken from interrogate windows of dimension $32 \mathrm{x}$ 16532 pixels with $50 \%$ of overlap between windows. Thus, there are 16 pixels $(\sim 1 \mathrm{~mm})$ between 1662 calculated vectors in both horizontal and vertical directions. A mean velocity field was 167 calculated from 700 couples of images. These images were taken on the symmetry plane and 
168 just above a black cup (height $\mathrm{x}$ diameter $=11 \mathrm{~cm} \times 8 \mathrm{~cm})$ filled with oil or water $(10 \mathrm{~cm}$

169 height). This is because the time average velocity vectors belong to this plan. In this way, the effect of 3D pattern is reduced.

\subsection{Air temperature fluctuations measurement}

173 To avoid as much as possible the flow disturbance in horizontal direction (air flows by fan 174 aspiration $\approx 0.03 \mathrm{~m} / \mathrm{s}$ ) and in vertical one (air flows by natural convection and by evaporation) 175 because of the presence of thermocouples, calibrated T-type fine thermocouples $(200 \mu \mathrm{m}$ diameter, precision $\pm 0.2^{\circ} \mathrm{C}$ ) were used to follow the air temperature fluctuations with time.

177 These thermocouples were tightened on a Plexiglas support $(5 \pm 0.1 \mathrm{~mm}$ space between 178 thermocouples shown in Fig. 3a). This support was placed at right angle to the airflow

179 direction to avoid the flow perturbation. Because of the very fine thermocouple diameter, 180 airflow was very slightly disturbed by their presence (the thermocouples occupy only $4 \%$ of 181 the flow cross-section). In our experiment, the air temperature was measured every second for $182 \mathrm{y}$ varying from $5 \mathrm{~mm}$ to $40 \mathrm{~mm}$ from the top of the cup while $\mathrm{x}$ was fixed at $68.5 \mathrm{~mm}$ (Fig. 183 3b).

\subsection{Experimental conditions}

186 The device was located in a test room with the controlled ambient temperature of $20^{\circ} \mathrm{C}$

187 (relative humidity about $60 \%$ ). The fan tension of $2.5 \mathrm{~V}$ allowed obtaining an air velocity of 188 about $0.03 \mathrm{~m} / \mathrm{s}$ in the work zone which is the order of magnitude of the one in a room (Plana-

189 Fattori et al., 2014). During experiment, the air velocity near the entrance of the work zone

190 was measured using an anemometer to assure that it was not modified because of the presence 191 of the cup. 
192 In order to study the influence of convection and evaporation on the airflow, the air velocity

193 field was measured (using PIV) above a cup filled with vegetable oil (boiling temperature

$194165^{\circ} \mathrm{C}$ ) and with water. The temperature of the oil was controlled at $20^{\circ} \mathrm{C}$ or $65^{\circ} \mathrm{C}$. The

195 temperature of water was controlled at several temperatures varying from 35 to $65^{\circ} \mathrm{C}$

196 (temperature of hot drink in general) using a heating resistance. An experiment was also

197 carried out without any cup.

198

199

\subsection{Measurement of convective heat transfer coefficient}

200 The convective heat transfer coefficient between the liquid in the cup and air was measured in

201 the work zone (Figure 4). The liquid (oil or water) in the cup was heated by a resistance 202 (supply power: Q) until $65^{\circ} \mathrm{C} \pm 1^{\circ} \mathrm{C}$ and this temperature was maintained during the 203 measurement (steady state). Once the steady state was reached, the air and liquid temperatures $204\left(\mathrm{~T}_{\text {air }}, \mathrm{T}_{\text {liq }}\right.$ respectively) were recorded every 10 s for about $50 \mathrm{~min}$ using a data logger, and then 205 the mean values were calculated. Two conditions were used: cup covered with an insulating 206 plate made of polystyrene $(8 \mathrm{~cm}$ diameter, $1 \mathrm{~cm}$ thickness, Figure $4 \mathrm{a})$ and un-covered cup 207 (Figure 4b). In the case of un-covered cup, the weight of the cup before and after experiment 208 was recorded in order to obtain the weight of evaporated water $(\Delta \mathrm{m})$.

209 It is to be reminded that the convective heat transfer coefficient is an average value over the 210 whole liquid surface. This coefficient determined at the liquid/air interface (h) can be 211 calculated by the following manner:

\section{Cup covered with insulating plate}

213 This experiment was carried out in order to quantify heat losses through the cup's wall ( $\left.\mathrm{Q}_{\text {loss }}\right)$ 214 while the heat loss through the insulating plate was neglected. At steady state, the heating 215 power supply to the resistance $\left(\mathrm{Q}_{1}\right)$ is equal to the heat losses. 
217 At steady state, the heating power supply to the resistance $\left(\mathrm{Q}_{2}\right)$ is equal to the sum of the heat 218 losses $\left(\mathrm{Q}_{\text {loss }}\right)$ through the cup wall, heat exchange by convection from the liquid surface to the 219 surrounding air $\left(\mathrm{Q}_{\text {conv }}\right)$ and heat exchange by water evaporation $\left(\mathrm{Q}_{\mathrm{evap}}\right)$.

$$
\mathrm{Q}_{1}=\mathrm{Q}_{\text {loss }}
$$

$$
\mathrm{Q}_{2}=\mathrm{Q}_{\text {loss }}+\mathrm{Q}_{\mathrm{conv}}+\mathrm{Q}_{\mathrm{evap}}
$$$$
\mathrm{Q}_{\mathrm{conv}}=\mathrm{h} * \mathrm{~A} *\left(\mathrm{~T}_{\text {liq }}-\mathrm{T}_{\text {air }}\right)
$$$$
\mathrm{Q}_{\text {evap }}=\Delta \mathrm{m} * \Delta \mathrm{h}_{\mathrm{evap}} / \Delta \mathrm{t}
$$

The convective heat transfer coefficient, $\mathrm{h}\left(\mathrm{Wm}^{-2} \mathrm{~K}^{-1}\right)$ can be calculated as below:

$$
\mathrm{h}=\frac{\mathrm{Q}_{\text {conv }}}{\mathrm{A}\left(\mathrm{T}_{\text {liq }}-\mathrm{T}_{\text {air }}\right)}=\frac{\mathrm{Q}_{2}-\mathrm{Q}_{1}-\Delta \mathrm{m} \times \Delta \mathrm{h}_{\text {evap }} / \Delta \mathrm{t}}{\mathrm{A}\left(\mathrm{T}_{\text {liq }}-\mathrm{T}_{\text {air }}\right)}
$$

231 It is to be reminded that for water at atmospheric pressure and for the temperature range used 232 in our study $\left(35-65^{\circ} \mathrm{C}\right), \Delta \mathrm{h}_{\text {evap }}$ is considered to be constant $\left(2.38 .10^{6} \mathrm{~J} / \mathrm{kg}\right)$ because the variation is low in this temperature range $\left(2.35 .10^{6}-2.42 .10^{6} \mathrm{~J} / \mathrm{kg}\right)$.

\section{Results and discussion}




\subsection{Analysis of airflow, heat and mass transfer above a cup of hot drink}

238 As cited previously, the airflow and heat transfer above a cup of hot drink can be 239 characterised by several dimensionless numbers. A drink cup can be considered as a truncated 240 cylinder with the hot walls at the top and the side. Our first approach consists in a calculation 241 of the order of magnitude of $\mathrm{Re}, \mathrm{Ra}$ and $\mathrm{Ri}$ allowing the information on the flow regimes 242 (laminar, turbulent) and the heat transfer mode (natural, forced and mixed convection). The 243 following values were used to estimate the dimensionless numbers; for the room: air 244 temperature $20^{\circ} \mathrm{C}$, velocity $0.03 \mathrm{~m} \cdot \mathrm{s}^{-1}$; for the cup: hot drink temperature $65^{\circ} \mathrm{C}$, cup dimension $2458 \mathrm{~cm}$ diameter $\mathrm{x} 11 \mathrm{~cm}$ height. The order of magnitude of the dimensionless number is 246 presented in Table 1.

247 Taking into account this analysis based on the dimensionless numbers, the airflow, heat and 248 vapour exchange between the drink and the air is expected to be a result of the interaction of 249 several phenomena. Considering the similarity with the flow along flat plate, since $\operatorname{Re}<5.10^{5}$ 250 and according to Incropera and Dewitt (1990), the boundary layer at the top should remain

251 laminar. In fact, the liquid/air interface is not at the top of the cup, so that the vortices could 252 appear behind the upper part of the cup wall. Considering the similarity to a partially hollow cylinder in our case, since $\operatorname{Re} \geq 90$, Karmann vortex detachment is expected. According to Rayleigh and Richardson numbers, natural convection is a determinant effect. So, to summarised, there is an upward warm air flow from the drink surface and this air is replaced by cooler air flowing downward from the ambient. There is instable airflow with vortex 257 shedding behind the cup. Additionally, water evaporates from the surface which contributes to 258 upward gas motion. The natural convection related to the temperature difference between the 259 hot drink and air should be more significant than the forced convection. 
one at $20^{\circ} \mathrm{C}$ is related to the heat exchange by natural convection. This exchange is influenced by the temperature difference between oil and air in the work zone. In the case of hot water at $65^{\circ} \mathrm{C}$, the airflow is related to the combined heat exchange by convection and evaporation. This evaporation can significantly contribute to the vertical velocity component at the surface of the liquid.

\subsection{Visualisation of airflow}

269 The images of airflow above the cup filled with water $\left(65^{\circ} \mathrm{C}\right)$ at 3 different moments are 270 shown in Figure 5. The heating resistance cable can be seen on the bottom right of these 271 images. The air flows upward because of water evaporation and the flow is oriented to the 272 right side because of air extraction by fans. It can be observed the unsteady flow with vortices 273 formation. From these images, pulse volatile aroma releases can be expected because the 274 plumes and vortices transport them from the liquid surface to the air.

\subsection{Influence of convection and evaporation on airflow}

277 The mean (time -averaged) velocity field calculated from 700 couple of images is presented 278 in Fig. 6 for 3 different cases: oil at $20^{\circ} \mathrm{C}$, oil at $65^{\circ} \mathrm{C}$ and water at $65^{\circ} \mathrm{C}$. The mean field is 279 used to facilitate the comparison of different situations in spite that it gives incomplete 280 information. The instantaneous field for given conditions can be significantly different but 281 they correspond to too large amount of information.

282 The cup of oil at $20^{\circ} \mathrm{C}$ (Fig. 6a) shows the influence of obstacle on airflow. In this case, air 283 flows above the cup with acceleration, first upward (at left) then downward (at right). Just 284 above the liquid surface inside the cup, there is an air recirculation. The recirculation above 285 obstacle was also observed by Martinuzzi and Tropea (1996). 
286 For the cup of oil at $65^{\circ} \mathrm{C}$ (Fig. 6b), air recirculation just above the liquid surface is observed 287 as in the case of oil at $20^{\circ} \mathrm{C}$. In this case, one can expect that air flows upward along the cup 288 by natural convection. This can explain why no downward airflow was observed in this case 289 at right.

290 For the cup of water at $65^{\circ} \mathrm{C}$ (Fig. 6c), the air recirculation just above the liquid surface 291 disappears while the upward flow is more noticeable.

292 Three profiles of horizontal $\left(\mathrm{v}_{\mathrm{x}}\right.$, main air flow direction) and vertical velocity $\left(\mathrm{v}_{\mathrm{y}}\right)$ were 293 extracted from the mean air velocity field along a vertical line above the cup and just 294 downstream $(\mathrm{x}=68.5 \mathrm{~mm})$. The results are shown in Fig.7.

295 All values of horizontal velocity $\mathrm{v}_{\mathrm{x}}$ are positive (Fig.7a), this means that air flows in the 296 horizontal direction from the left to the right. $v_{x}$ decreases form $y=0$ to $y \approx 5 \mathrm{~cm}$, this 297 represents the zone of influence of the obstacle. Airflow is less disturbed by the presence of 298 the cup for $\mathrm{y}>5 \mathrm{~cm}$. The $\mathrm{v}_{\mathrm{x}}$ profiles are similar for the 3 cases: oil $\left(20^{\circ} \mathrm{C}\right)$, oil $\left(65^{\circ} \mathrm{C}\right)$, water $299\left(65^{\circ} \mathrm{C}\right)$.

300 The vertical velocity profiles $\mathrm{v}_{\mathrm{y}}$ are quite different (Fig. $7 \mathrm{~b}$ ). Only the case of oil at $20^{\circ} \mathrm{C}$ 301 shows negative velocity for $0<\mathrm{y}<4 \mathrm{~cm}$. This is a result of downward airflow behind the cup 302 after the flow above it. When the temperature of the liquid is higher than the one of upstream 303 air, air flows upward because of the effect of natural convection. This effect is more 304 significant for evaporable liquid.

\subsection{Influence of water temperature on airflow}

307 The mean air velocity field for cup filled with water at $35^{\circ} \mathrm{C}, 45^{\circ} \mathrm{C}, 55^{\circ} \mathrm{C}$ and $65^{\circ} \mathrm{C}$ is shown 308 in Fig. 8. The effect of water temperature on the airflow pattern (upward flow) becomes really 
significant when temperature is higher than $55^{\circ} \mathrm{C}$. This can be explained by the non linearity

310 between saturated pressure of water and its temperature. Indeed, at $35^{\circ} \mathrm{C}$, for example, the

311 saturation vapour pressure is only about $6 \mathrm{kPa}$, that means that at the liquid/air interface water

312 vapour represents only $6 \%$ of the molar fraction. Therefore the evaporation effect is small.

313 Increasing the temperature from $35^{\circ} \mathrm{C}$ to $45^{\circ} \mathrm{C}$ increases the vapour fraction by only $4 \%$. At

$31455^{\circ} \mathrm{C}$, the vapour fraction becomes about $16 \%$ and a slight modification of flow pattern can be

315 observed. At $65^{\circ} \mathrm{C}$, water vapour represents $25 \%$ of molar fraction at the liquid/air interface.

316 The evaporation effect becomes obvious. The natural convection effect is due partly to the

317 temperature difference $\Delta \rho / \rho \approx \Delta \mathrm{T} / \mathrm{T} \approx 7 \%$ and partly to molar weight

318 difference $\Delta \rho / \rho \approx x\left(M_{\text {air }}-M_{\text {water }}\right) / M_{\text {air }} \approx 10 \% \quad\left(M_{\text {air }}=29 \mathrm{~g} / \mathrm{mol}, M_{\text {water }}=18 \mathrm{~g} / \mathrm{mol}\right)$. From

319 the flow pattern at $65^{\circ} \mathrm{C}$, it can be expected that aroma compounds can be entrained

320 efficiently by the evaporated water.

\subsection{Air temperature and velocity fluctuations}

322 The air temperature measured every second for $\mathrm{y}=5,10,20,30$ and $40 \mathrm{~mm}$ and $\mathrm{x}=68.5 \mathrm{~mm}$ is 323 presented in Fig. 9 for the cups of oil and water at $65^{\circ} \mathrm{C}$. The same variation cycles can be 324 observed for every position. This figure also shows the air velocity magnitude extracted from 32520 PIV images measured every $0.25 \mathrm{~s}$, fluctuations are also observed. This is because of the 326 strong relation between air temperature and velocity when natural convection is the dominant 327 heat transfer mode.

328 The mean and standard deviation of temperature (3600 measurements, duration 3600s) and 329 velocity (800 measurements, duration 200s) are reported in Table 2. For both cases (oil and 330 water), the air temperature decreases with the height (y) while the air velocity increases.

331 The difference of temperature fluctuations for the cups of oil and water can be explained by 332 the difference of involved phenomena. The main heat exchange for the cup of oil is natural 
333 convection. For the cup of water, the combined natural convection and water evaporation

334 leads to the intermittent detachment of hot and humid air plumes above it. The upward flow of 335 hot and humid air is balanced by the downward flow of cold and dry ambient air. This 336 explains the more temperature variations with time and the higher temperature decrease with 337 the height for the water cup.

338 For an isothermal flow around an infinite cylinder of the same diameter as the cup, $339\left(\operatorname{Re}_{\mathrm{D}}=150\right.$, see Table 1), Strouhal number is about 0.18 and the frequency of vortex 340 shedding of $0.07 \mathrm{~Hz}$ is estimated. This frequency is in the range of the observed fluctuations 341 of several seconds. But the interaction with the detachment of the plumes (due to the 342 combined natural convection and evaporation) and the airflow near the upper surface made 343 certainly the phenomena more complex and un-periodic. It is to be emphasized that a Fourier 344 Transform was carried out; however, no specific frequency could be identified. This means 345 that these fluctuations are rather random.

\section{$346 \quad$ 3.6. Heat transfer coefficient between air and water}

347 The experimental values of the heat flux (Q) are shown in Table 3. Without evaporation, the 348 convective heat transfer coefficient at the liquid/air interface is $18.7 \mathrm{~W} \cdot \mathrm{m}^{-2} \mathrm{~K}^{-1}$ (cup of oil at $34965^{\circ} \mathrm{C}$ ). For laminar flow over an isothermal horizontal flat plate, heat transfer coefficients by 350 natural and forced convection of 6.7 and $7.4 \mathrm{~W} \cdot \mathrm{m}^{-2} \cdot \mathrm{K}^{-1}$ were obtained respectively 351 (calculation based on the equations 1 and 3 and for $\mathrm{D}=8 \mathrm{~cm}$ ). The experimental value is 352 almost equal to the sum of these values. For the cup of water at $65^{\circ} \mathrm{C}$, it can be observed that 353 the heat flux due to the latent heat of evaporation $\left(\mathrm{Q}_{\mathrm{evap}}\right)$ is more than 3 times higher than the 354 convective flux. The presence of evaporation enhance also the convective flux, the heat 355 transfer coefficient is indeed increased from 18.7 to $24.9 \mathrm{~W} \cdot \mathrm{m}^{-2} \mathrm{~K}^{-1}$. 
356 The air velocity due to evaporative airflow is about $0.003 \mathrm{~m} . \mathrm{s}^{-1}$. This estimation is based on

357 the weight loss during the experiment of the cup filled with water $\left(\mathrm{v}=\frac{\Delta \mathrm{m}}{\Delta \operatorname{t\rho A}}\right)$.

358 From these results, the cooling rate of a well-insulated cup of hot drink or of a non-insulated

359 cup can be estimated. In the first case, the heat loss is only by convection and evaporation at

360 the top (liquid/air interface, $\mathrm{h} \approx 25 \mathrm{Wm}^{-2} \mathrm{~K}^{-1}$, cf. Table 3), the heat loss is about $6 \mathrm{~W}$ and the

361 cooling rate about $0.35^{\circ} \mathrm{C} / \mathrm{min}$. In the second case, there are also heat losses through the side

362 walls $\left(\mathrm{h} \approx 10 \mathrm{Wm}^{-2} \mathrm{~K}^{-1}\right)$ and the cooling rate is about $1^{\circ} \mathrm{C} / \mathrm{min}$.

\section{4. Conclusion}

364 An attempt was carried out in this study to understand the mechanism of airflow above the 365 cup with the objective to have a quantitative heat and mass transfer analysis and to gain 366 knowledge which will be transposable to indoor aroma compound dispersion in relation with 367 the ambient smell perceived by consumer. The airflow measurement by PIV over the cup 368 filled with hot water shows that the flow is unsteady with vortex formation. This suggests 369 pulsative release of aroma compounds from a hot drink. The air velocity varies both due to the 370 position and the time. This complexity is related to the instantaneous heat exchanges by 371 convection and evaporation between the water and surrounding air coupled with the unsteady 372 flow expected behind the cup.

373 An experimental methodology was developed to determine the heat transfer coefficient 374 between a cup of hot drink and ambient air. This parameter allows the prediction of the 375 cooling rate of a drink in room condition.

\section{ACKNOWLEDGEMENTS}

377 The authors thank Daniel Picque, David Leveque and Jerome Bussière for their help in the 378 construction of the device allowing temperature and air velocity in controlled conditions.

379 They also thank Gail Wagman for her precious help in revising the English. 


\section{References}

381 Alamyane A.A. and Mohamad A.A., 2010. Simulation of forced convection in a channel with 382 extended surfaces by the lattice Boltzmann method. Computers and Mathematics with Applications, 59, 2421-2430.

384 Carey, M.E., Asquith, T., Linforth, R.S.T., Taylor, A.J., 2002. Modeling the partition of 385 volatile aroma compounds from a cloud emulsion. Journal of Agricultural and Food 386 Chemistry, 50, 1985-1990.

387 Chyu M.K. and Natarajan V., 1996. Heat transfer on the base surface of three dimensional 388 protruding elements. International Journal Heat and Mass Transfer, 39, 2925-2935.

Deleris I., Zouid I., Souchon I., Tréléa I.C., 2009. Calculation of apparent diffusion 390 coefficients of aroma compounds in dairy emulsions based on fat content and 391 physicochemical properties in each phase. Journal of Food Engineering, 94, 205-214.

392 Incropera F.P. and Dewitt D.P., 1990. Fundamentals of Heat and Mass Transfer. New York: 393 Wiley.

394 Doulia, D., Tzia, K., Gekas, V., 2000. A knowledge base for the apparent mass diffusion 395 coefficient (DEFF) in foods. International Journal of Food Properties. 3 (1), 1-14.

396 Doyen, K., Carey, M.E., Linforth, R.S.T., Marin, M., Taylor, A.J., 2001. Volatile release from 397 an emulsion: headspace and in-mouth studies. Journal of Agricultural and Food Chemistry, $39849(2), 804-810$.

399 Giroux, H.J., Perreault, V., Britten, M., 2007. Characterization of hydrophobic flavour release 400 profile in oil-in-water emulsions. Journal of Food Science, 72 (2), S125-S129.

401 Hall C. W., 2000. Laws and Models: Science, Engineering and Technology, Boca Raton, 402 CRC Press, 524 p. 
Incropera F.P. and DeWitt D.P., 1996. Fundamentals of Heat and Mass Transfer, John Wiley

$404 \&$ Sons, INC. $4^{\text {ème }}$ edition, New York, Chapter 6 and 9, 886 p.

405 Jubran B.A., Swiety S.A., Hamdan M.A., 1996. Convective heat transfer and pressure drop 406 characteristics of various array configurations to simulate the cooling of electronic equipment, 407 International Journal Heat and Mass Transfer, 39, 3519-3529.

408 Landy, P., Rogacheva, S., Lorient, D., Voilley, A., 1998. Thermodynamic and kinetic aspects 409 of the transport of small molecules in dispersed systems. Colloids and Surfaces Biointerfaces, $410 \quad 12,57-65$.

411 Mamun, M.A.H., Rahman M.M., Billah M.M., Saidur R., 2010. A numerical study on the 412 effect of a heated hollow cylinder on mixed convection in a ventilated cavity, International 413 Communications in Heat and Mass Transfer, 37, 1326-1334.

414 Marin M, Baek I, Taylor A.J., 1999. Volatile release from aqueous solutions under dynamic 415 headspace dilution conditions, Journal of Agricultural and Food Chemistry, 47(11), 47504164755.

417 Martinuzzi R., Tropea C., 1996. The flow around surfaced-mounted, prismatic obstacles 418 placed in a fully developed channel flow, Journal Fluids Engineering, 115, 85-92.

419 Meynier, A., Lecoq, C., Genot, C., 2005. Emulsification enhances the retention of esters and 420 aldehydes to a greater extent than changes in the droplet size distribution of the emulsion. 421 Food Chemistry, 93 (1), 153-159.

422 Moussaoui M.A., Jami M., Mezrhab A., Naji H., 2010. MRT-Lattice Boltzmann simulation of 423 forced convection in a plane channel with an inclined square cylinder, International Journal 424 of Thermal Sciences, 49, 131-142.

425 Plana-Fattori A., Trelea I.C., Le Page J.F., Souchon I., Pollien P., Ali S., Ramaioli M., 426 Pionnier-Pineau E., Hartmann C., Flick D., 2014. A novel approach for studying the indoor 
dispersion of aroma through computational fluid dynamics, Flavour and Fragrance Journal, 29 (3), 143-156.

Philippe, E., Seuvre, A.M., Colas, B., Langendorff, V., Schippa, C., Voilley, A., 2003. Behavior of flavor compounds in model food systems: a thermodynamic study. Journal of Agricultural and Food Chemistry, 51, 1393-1398.

Rabe, S., Krings, U., Berger, R.G., 2004. Dynamic flavour release from miglyol/water emulsions: modelling and validation. Food Chemistry, 84 (1), 117-125.

Rahman, M.M., Alim, M.A., Saha, S., Chowdhury, M.K., 2008. Mixed convection in a vented square cavity with a heat conducting horizontal solid circular cylinder, J. Nav. Arch. Mar. Eng, 5 (2) 37-46.

Rahman, M.M., Alim, M.A., Mamun M.A.H., 2009. Finite element analysis of mixed convection in a rectangular cavity with a heat-conducting horizontal circular cylinder, Nonlinear analysis, Model. Control 14 (2) 217-247.

Relkin, P., Fabre, M., Guichard, E., 2004. Effect of fat nature and aroma compound hydrophobicity on flavor release from complex food emulsions. Journal of Agricultural and Food Chemistry, 52 (20), 6257-6263.

Roberts, D.D., Pollien, P., Antille, N., Lindinger, W., Yeretzian, C., 2003. Comparison of nosespace, headspace, and sensory intensity ratings for the evaluation of flavour absorption by fat. Journal of Agricultural and Food Chemistry, 51 (12), 3636-3642.

Overbosch, P., Afterof, W.G.M., Haring, P.G.M., 1991. Flavor release in the mouth, Food Reviews International, 7 (2) 137-184.

Shah K., Ferizer J.H., 1997, A fluid mechanicians view of wind engineering: Large eddy simulation of flow past a cubic obstacle, Journal of Wind Engineering and Industrial Aerodynamics, 67-68, 211-224. 
451 Sparrow E.M., Niethammer J.E., Chaboki A., 1982. Heat transfer and pressure drop 452 characteristics of arrays of rectangular modules encountered in electronic equipment. 453 International Journal Heat and Mass Transfer, 25, 961-973.

454 Sparrow E.M., Yanezmoreno A.A., Otis D.R., 1984. Convective heat transfer response to 455 height differences in an array of block like electronic components. International Journal Heat 456 and Mass Transfer, 27, 469-473.

457 Stroebele N, De Castro JM., 2004. Effect of ambience on food intake and food choice. $458 \quad$ Nutrition, 20(9) 821-38.

459 Taylor, A.J., Linforth, R.S.T., 1996. Flavour release in the mouth. Trends in Food Science 460 and Technology, 7 (12), 444-448.

461 Yong T.J. and Vafai K., 1998. Convective cooling of a heated obstacle in a channel, 462 International Journal Heat and Mass Transfer, 41, 3131-3148.

463 Wietrzak A. and Poulikakos D., 1990. Turbulent forced convective cooling of microelectronic 464 devices, International Journal Heat and Mass Transfer, 11, 105-113.

465 


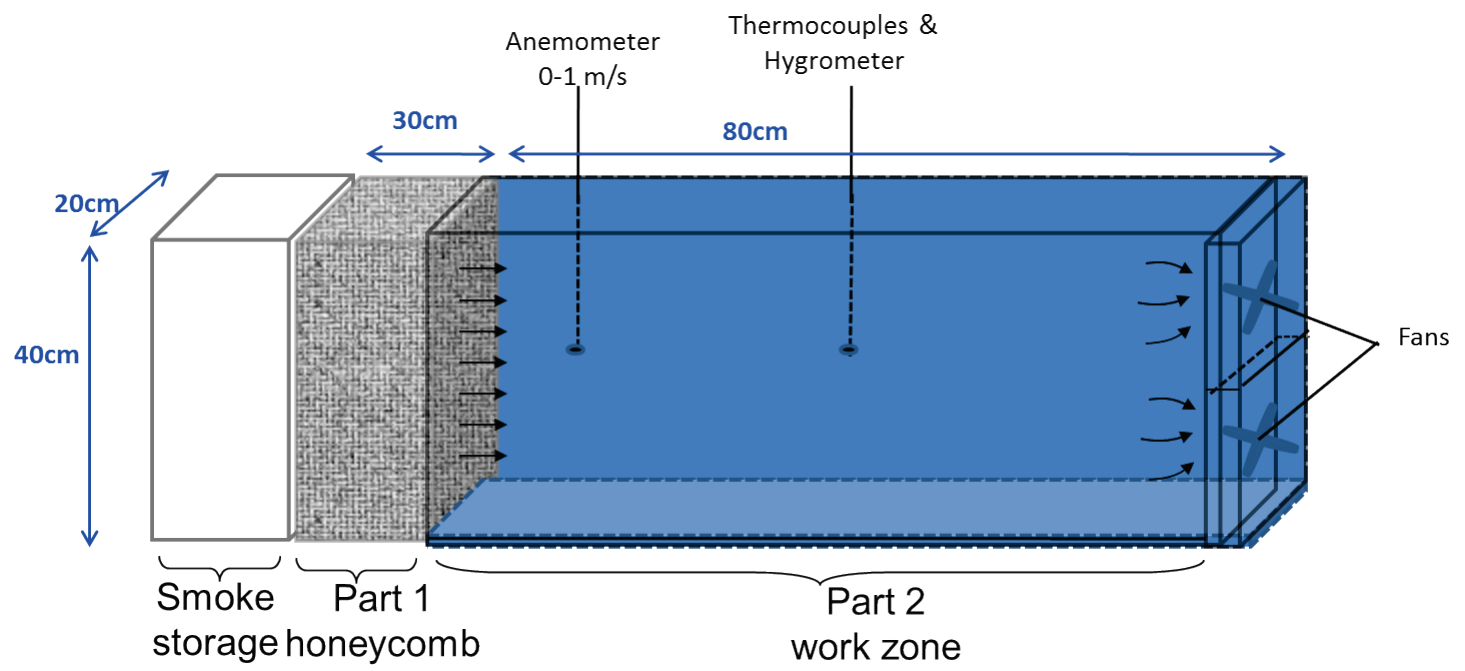

Figure 1: Experimental device 


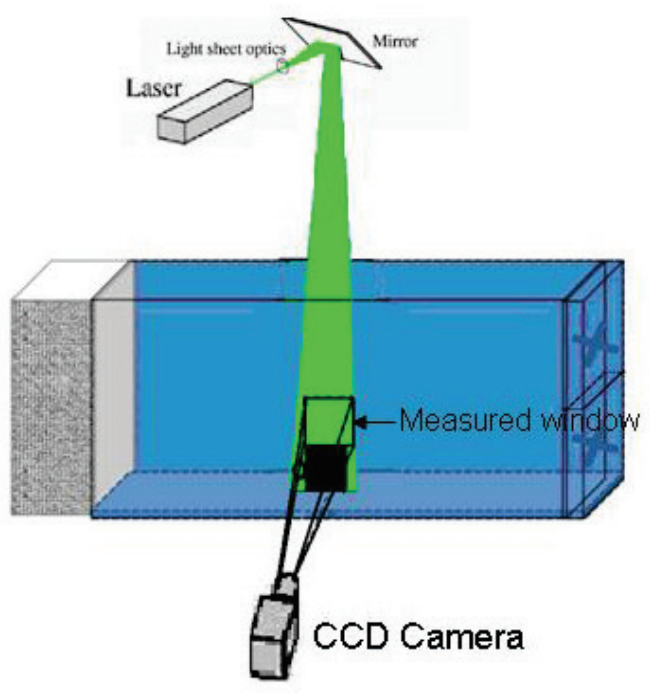

Figure 2: Position of laser beam, camera and measured window. 


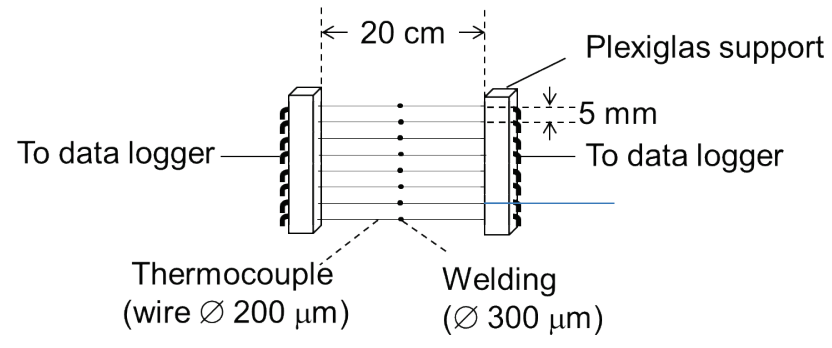

(a)

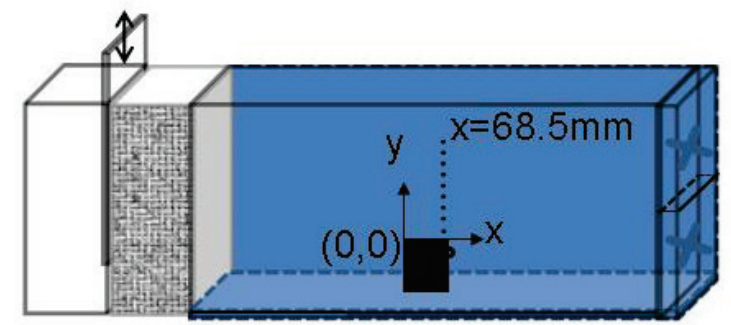

(b)

Figure 3: a-Fixation device of 8 fine thermocouples (front view) b-Position of air temperature measurement above the cup. 


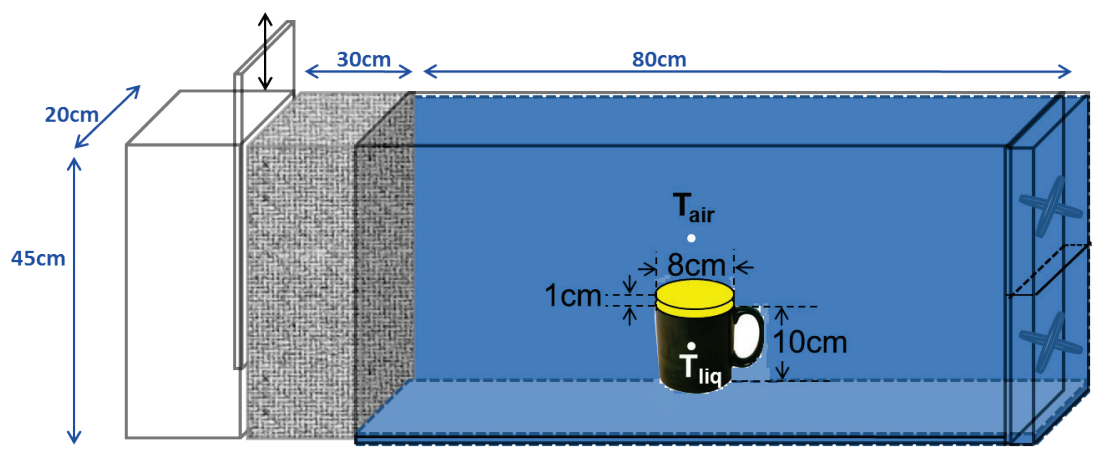

(a)

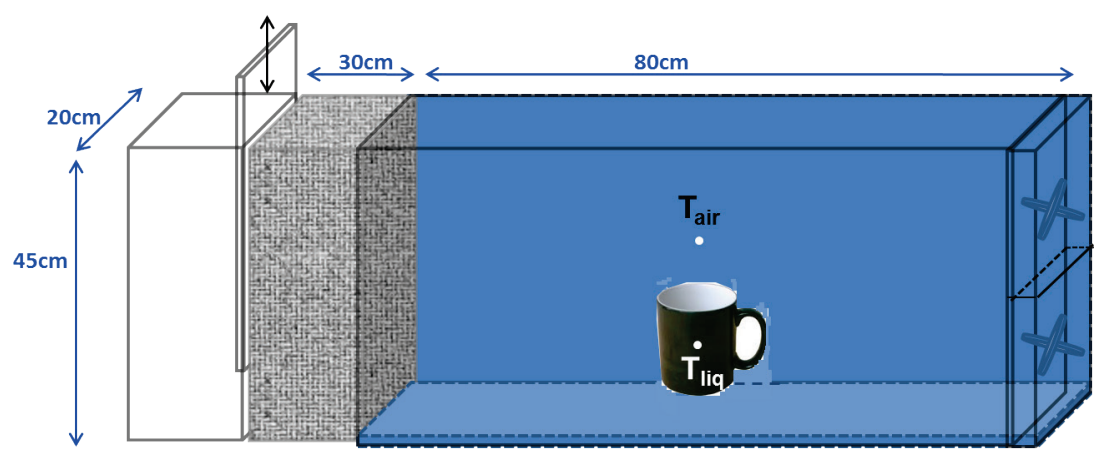

(b)

Figure 4: Heat transfer coefficient measurement

(a)- Cup covered with insulating plate (b)- Un-covered cup 


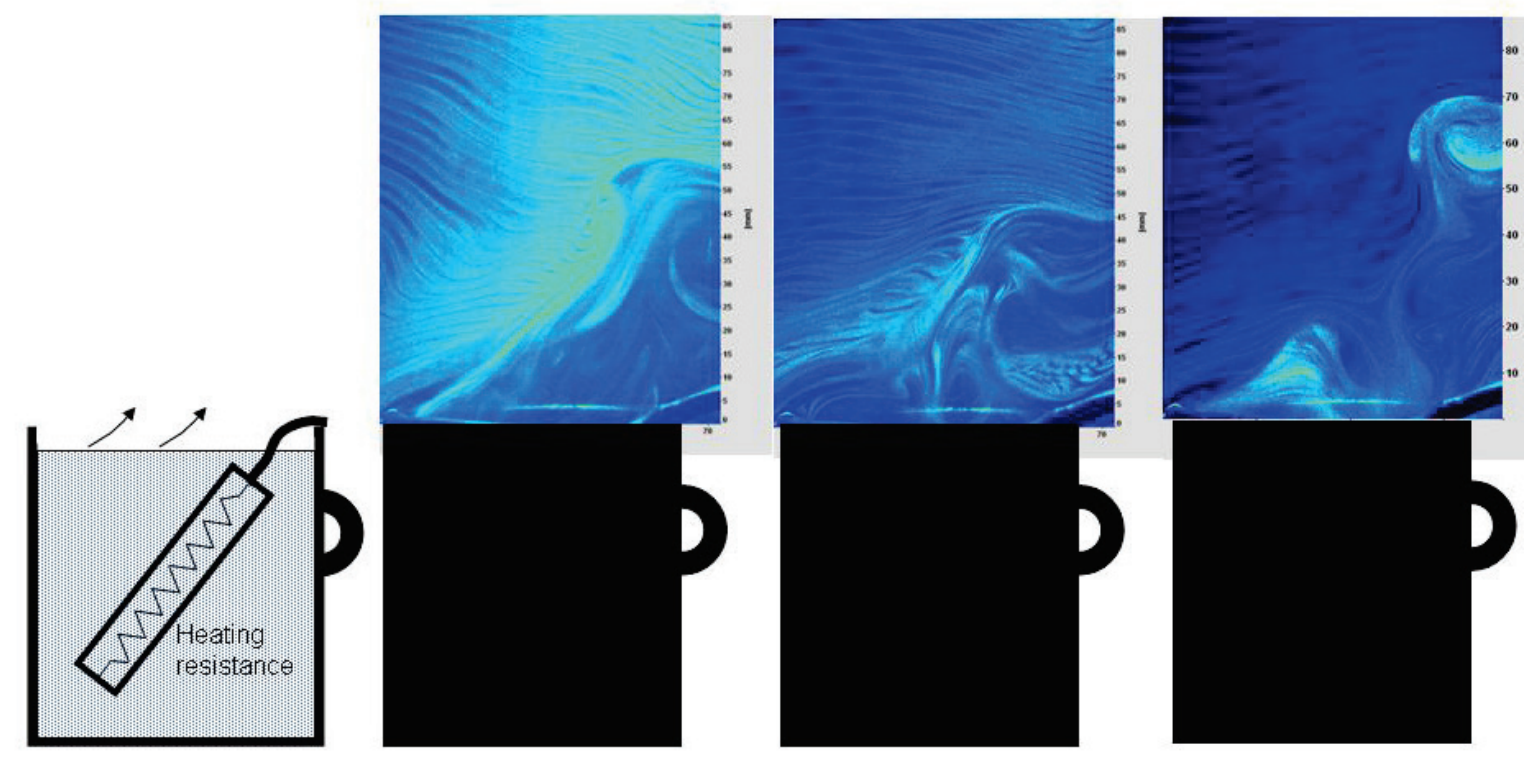

Figure 5: Images of airflow above the cup filled with water $\left(65^{\circ} \mathrm{C}\right)$ at 3 different moments. 


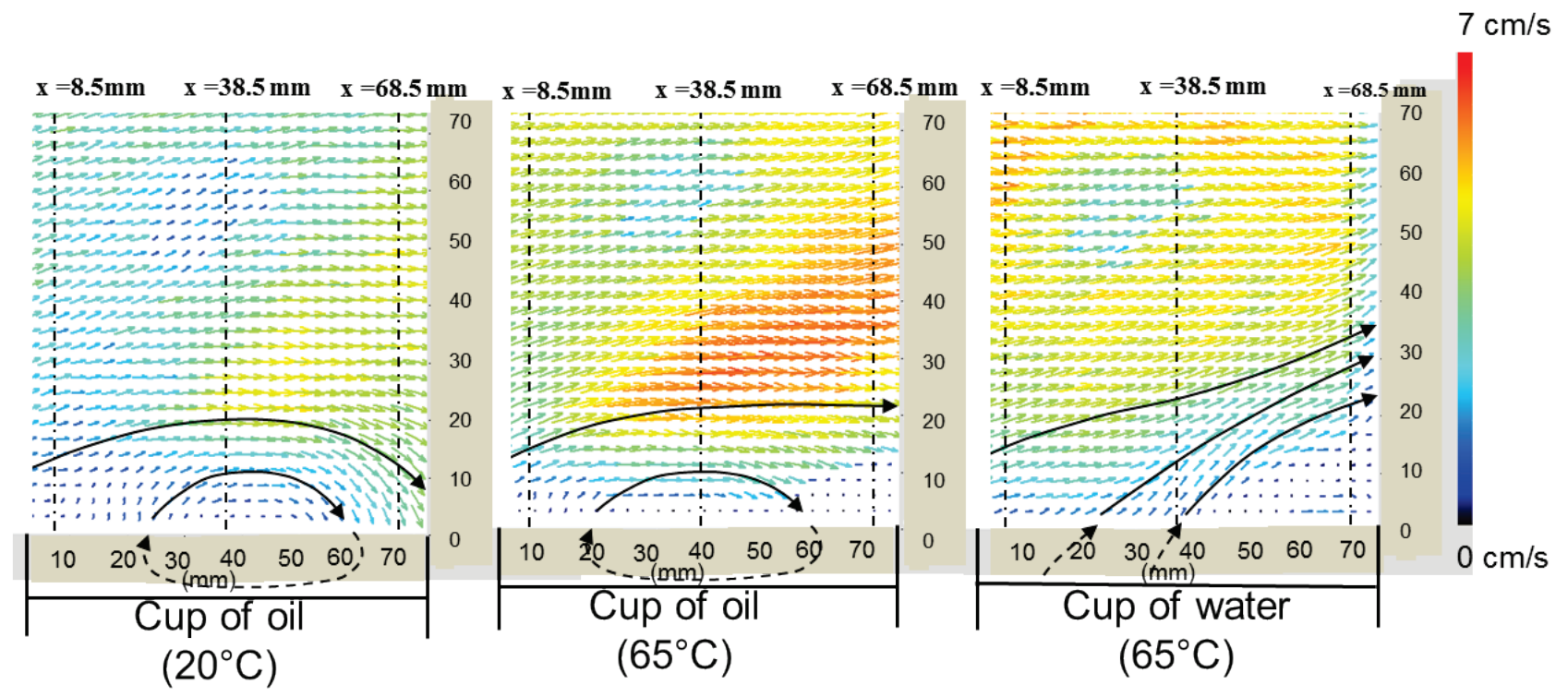

(a)

(b)

(c)

Figure 6: Mean air velocity field (mean of 700 measurements) above the cup filled with (a)vegetable oil at $20^{\circ} \mathrm{C}(\mathrm{b})$ - vegetable oil at $65^{\circ} \mathrm{C}$ (c)- water at $65^{\circ} \mathrm{C}$. Solid black lines represent the flow direction. 

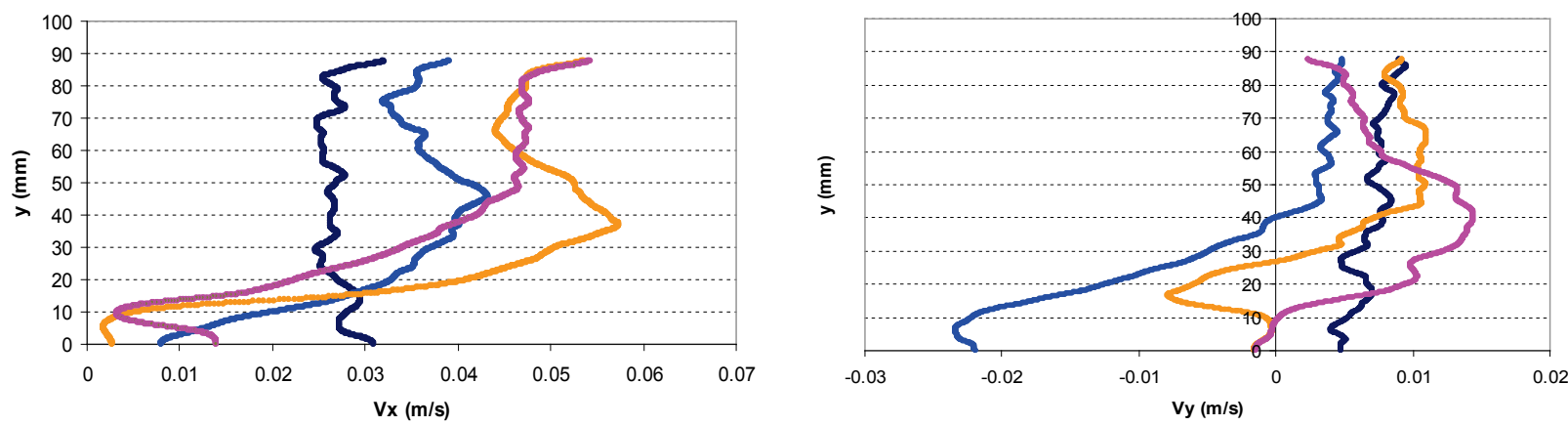

$\rightarrow$ Without cup $\rightarrow$ Oil $\left(20^{\circ} \mathrm{C}\right) \longrightarrow$ Oil $\left(65^{\circ} \mathrm{C}\right) \rightarrow$ Water $\left(65^{\circ} \mathrm{C}\right)$

(a)

(b)

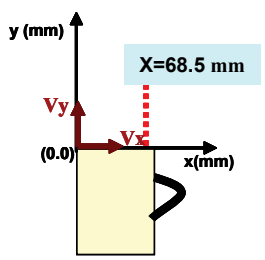

Figure 7: Mean air velocity at $\mathrm{x}=68.5 \mathrm{~mm}$ for the device without cup, cup filled with oil at $20^{\circ} \mathrm{C}$, oil at $65^{\circ} \mathrm{C}$ and water at $65^{\circ} \mathrm{C}\left(\right.$ a)- horizontal velocity, $v_{x}\left(\right.$ b)- vertical velocity, $v_{y}$. 


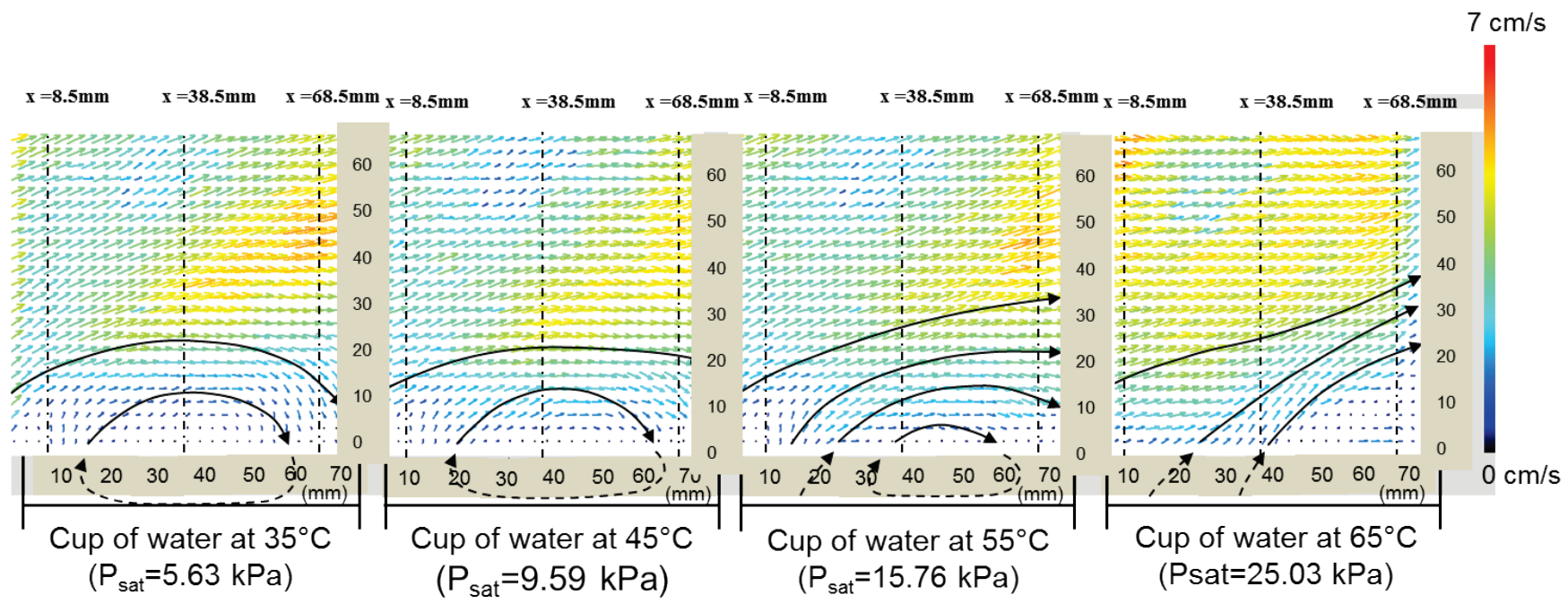

(a)

(b)

(c)

(d)

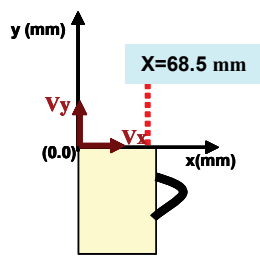

Figure 8: Mean air velocity field above the cup filled with water at different temperatures (a) $35^{\circ} \mathrm{C}$ (b) $45^{\circ} \mathrm{C}$ (c) $55^{\circ} \mathrm{C}$ (d) $65^{\circ} \mathrm{C}$. Solid black lines represent the flow direction. 

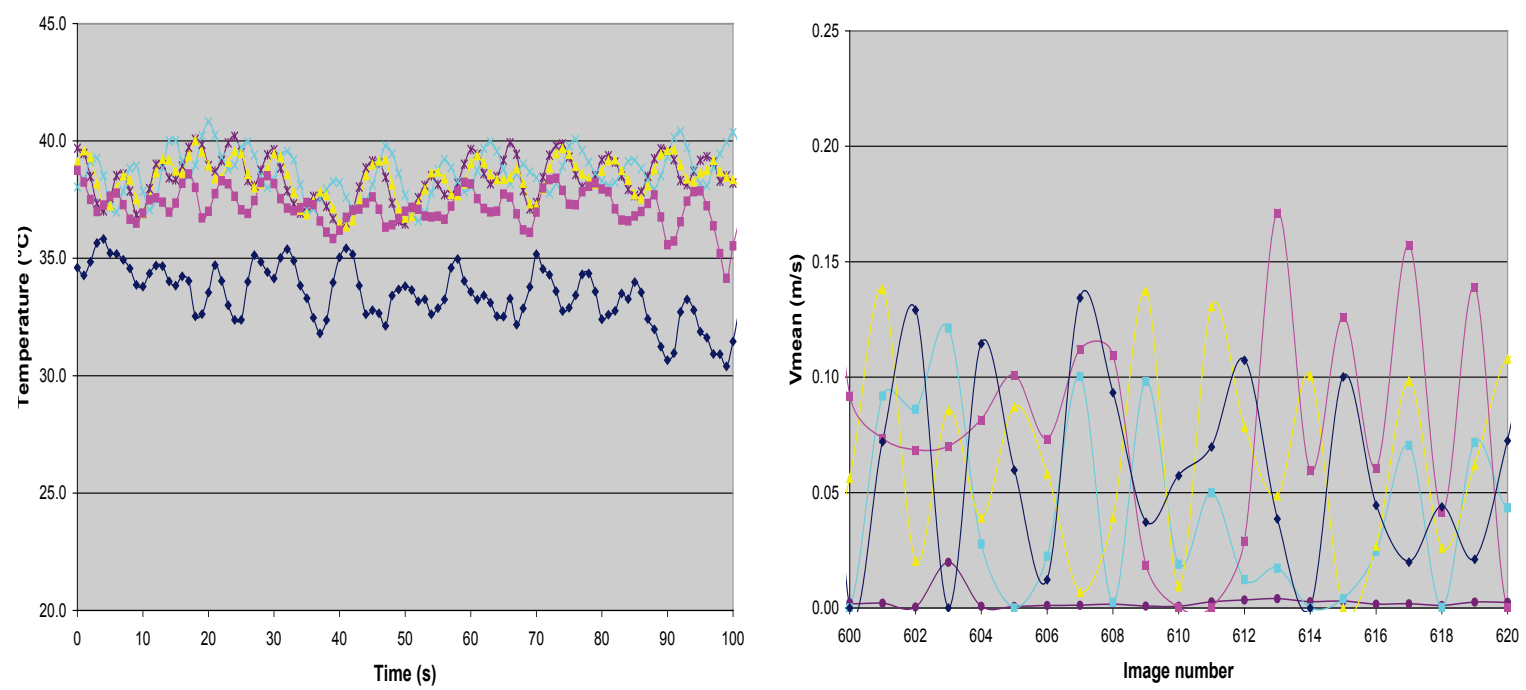

a-Cup of oil $\left(65^{\circ} \mathrm{C}\right)$
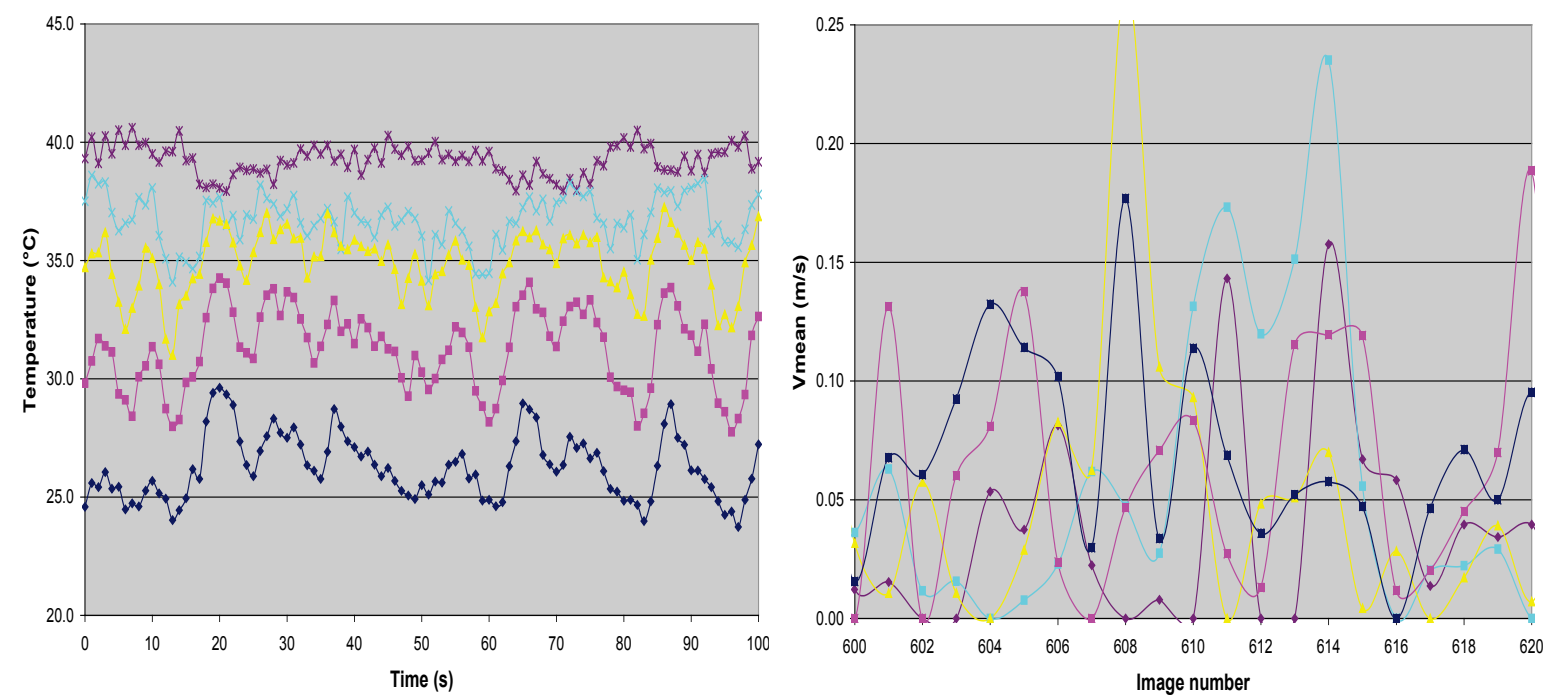

b-Cup of water $\left(65^{\circ} \mathrm{C}\right)$
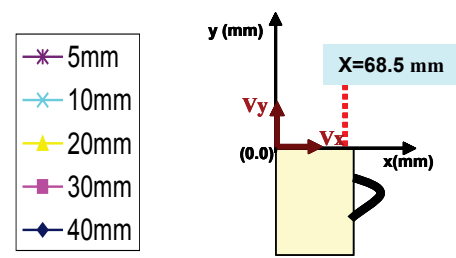

Figure 9: Air temperature fluctuations at $\mathrm{y}=5,10,20,30$ and $40 \mathrm{~mm}$ for $\mathrm{x}=68.5 \mathrm{~mm}$ and air velocity magnitude measured every $0.25 \mathrm{~s}$. 
Table 1: Order of magnitude of dimensionless numbers for a cup of hot drink placed in a room.

\begin{tabular}{|c|c|l|}
\hline \multirow{2}{*}{$\begin{array}{c}\text { Dimensionless } \\
\text { number }\end{array}$} & Value & \multicolumn{1}{|c|}{ Interpretation } \\
\hline $\mathrm{Re}_{\mathrm{D}}$ & 150 & $\mathrm{Re} \leq 5.10^{5}$, laminar airflow over the hot drink cup \\
\cline { 3 - 4 } & & $\mathrm{Re} \geq 90$, Karman vortex street downstream of the \\
& $2.1 \times 10^{6}$ & $10^{4} \leq \mathrm{Ra} \leq 10^{7}$, laminar airflow by natural convection \\
& & over the hot drink cup \\
\hline $\mathrm{Ri}$ & 124 & $\mathrm{Ri}>10$, natural convection between the drink and the \\
& & surrounding air is the dominant heat transfer mode. \\
\hline
\end{tabular}


Table 2: Mean and standard deviation of air temperature and velocity at various heights (y) for $\mathrm{x}=68.5 \mathrm{~cm}$.

\begin{tabular}{|c|c|c|c|c|c|c|c|c|}
\hline \multirow[t]{3}{*}{$\mathrm{y}(\mathrm{mm})$} & \multicolumn{4}{|c|}{ Cup of oil $\left(65^{\circ} \mathrm{C}\right)$} & \multicolumn{4}{|c|}{ Cup of water $\left(65^{\circ} \mathrm{C}\right)$} \\
\hline & \multicolumn{2}{|c|}{ Temperature $\left({ }^{\circ} \mathrm{C}\right)$} & \multicolumn{2}{|c|}{$\begin{array}{c}\text { Velocity } \\
\text { magnitude }(\mathrm{m} / \mathrm{s})\end{array}$} & \multicolumn{2}{|c|}{ Temperature $\left({ }^{\circ} \mathrm{C}\right)$} & \multicolumn{2}{|c|}{$\begin{array}{c}\text { Velocity } \\
\text { magnitude }(\mathrm{m} / \mathrm{s})\end{array}$} \\
\hline & Mean & Std & Mean & Std & Mean & Std & Mean & Std \\
\hline 5 & 38.43 & 0.94 & 0.0043 & 0.0103 & 39.24 & 0.65 & 0.0396 & 0.0430 \\
\hline 10 & 38.68 & 0.93 & 0.0481 & 0.0515 & 36.73 & 1.04 & 0.0529 & 0.0517 \\
\hline 20 & 38.40 & 0.83 & 0.0668 & 0.0576 & 34.89 & 1.35 & 0.0539 & 0.0535 \\
\hline 30 & 37.20 & 0.77 & 0.0732 & 0.0566 & 31.23 & 1.68 & 0.0619 & 0.0539 \\
\hline 40 & 33.47 & 1.19 & 0.0732 & 0.0520 & 26.24 & 1.36 & 0.0663 & 0.0546 \\
\hline
\end{tabular}


Table 3: Convective heat transfer coefficient between oil-air and water-air.

\begin{tabular}{|c|c|c|}
\hline Parameter & $\begin{array}{c}\text { Convection } \\
\text { (cup filled with oil at } 65^{\circ} \mathrm{C} \text { ) }\end{array}$ & $\begin{array}{l}\text { Convection+ evaporation } \\
\text { (cup filled with water at } 65^{\circ} \mathrm{C} \text { ) }\end{array}$ \\
\hline $\mathrm{Q}_{\mathrm{Conv}} / \mathrm{A}\left(\mathrm{W} \cdot \mathrm{m}^{-2}\right)$ & 795 & 1099 \\
\hline $\mathrm{Q}_{\text {Evap }} / \mathrm{A}\left(\mathrm{W} . \mathrm{m}^{-2}\right)$ & 0 & 3547 \\
\hline$\Delta \mathrm{m} / \Delta \mathrm{t}(\mathrm{kg} / \mathrm{s})$ & 0 & $5.73 \times 10^{-6}$ \\
\hline $\mathrm{h}\left(\mathrm{W} \cdot \mathrm{m}^{-2} \cdot \mathrm{K}^{-1}\right)$ & 18.7 & 24.9 \\
\hline
\end{tabular}

